
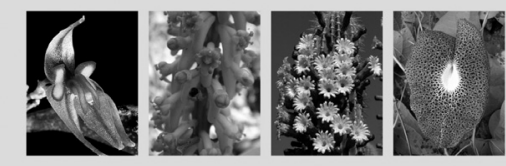

Diversidad florística de Oaxaca: de musgos a angiospermas (colecciones y lista de especies) Abisai Josué Garcta-Mendoza, cthory complah

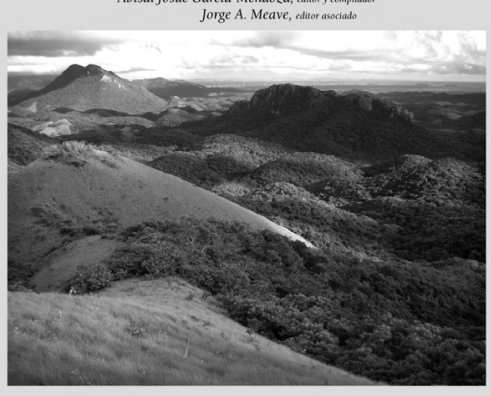

$\mathbf{R}$ e-parafraseando una cita clásica, tendría que decir que la botánica es ella y sus circunstancias. Debido a la realidad nacional, cuando el país parece que se nos cae a pedazos, es doblemente admirable que 127 botánicos decidan construir algo de patria. Quizá parezca insensato decir que un libro es un pilar para un país como el nuestro, pero estoy convencido de que éste sí puede ser un gran cimiento de conocimiento y de desarrollo para nuestro México.

En el libro Diversidad florística de Oaxaca: de musgos a angiospermas (colecciones y lista de especies) se ha logrado uno de los mayores retos que los botánicos han emprendido en las últimas décadas. Este desafío consistió en la elaboración de la lista de las especies de plantas presentes en el estado de Oaxaca, el cual se perfila como el más diverso del país.

La riqueza florística de Oaxaca es de la misma magnitud que la de algunos países centroamericanos que tradicionalmente se han destacado por la di-

\title{
Bi Sti Bidó' (el aliento creador): EL INVENTARIO DE PLANTAS DE UN ESTADO DE GRAN DIVERSIDAD
}

\author{
García Mendoza A.J. y Meave J.A. Eds. \\ DIVERSIDAD FLORÍSTICA DE OAXACA: DE MUSGOS A ANGIOSPERMAS \\ (COLECCIONES Y LISTA DE ESPECIES)
}

\begin{abstract}
Universidad Nacional Autónoma de México y Comisión Nacional para el Conocimiento y Uso de la Biodiversidad, México, D.F., 352 páginas. 2011.
\end{abstract} ISBN: 978-607-02-2434-8

versidad de su flora como Costa Rica. En total, en esta obra se presentan los nombres de 9,362 especies de plantas (8,903 excluyendo los musgos), y además se reconoce la existencia en el estado de 227 taxones pertenecientes a categorías infraespecíficas. Aunado a esto, la flora de Oaxaca resalta por el gran contenido de especies endémicas, ya sea de México o incluso del estado. El libro incluye cuadros que sintetizan la información sobre la riqueza y los endemismos de los diferentes grupos florísticos estudiados. Si bien esta información es de mucha utilidad, en realidad no alcanza a reflejar todo el valor de la flora de Oaxaca. Por ejemplo, en algunos casos estas especies endémicas son verdaderas rarezas botánicas, ya sea porque son especies microendémicas o porque se pueden considerar como paleoendemismos. La lista florística incluye una gama impresionante de linajes evolutivos, representados por más de 320 familias y 2,160 géneros diferentes, de modo que tan sólo ojear la lista es equivalente a estar en una cátedra de evolución y de botánica general.

Como amante de las plantas, no puedo dejar de asombrarme de que en Oaxaca haya 20 especies de cícadas, 17 de licopodios, 47 de selaginelas, 17 de pinos, 50 de encinos, 12 de aristoloquias; casi que en cualquier grupo florístico que uno revise hay una grata sorpresa. Además, hay otras muchas razones para maravillarse con esta flora. Por ejemplo, el potencial hortícola es sobresaliente, dado que existen 41 especies del género Begonia, 121 cactáceas, 189 bromeliáceas, y 715 orquídeas, por citar algunos ejemplos. Hay muchas preguntas que surgen de una revisión de la lista, desde la magnánima ¿por qué hay esta gran diversidad de plantas en Oaxaca?, o ¿por qué hay grupos muy diversificados, ya sea a nivel de familia o a nivel de género? Particularmente para esta última cuestión, ¿cómo se puede explicar que en Oaxaca haya 123 especies de Tillandsia, 84 de Salvia y 78 de Ipomoea? 
Habrá otras preguntas más puntuales como: ¿con cuál de las 41 especies de Bursera oaxaqueñas se podrán fabricar los mejores alebrijes? ¿Cómo quedaré después de tomar un caballito de mezcal de cada una de las 18 especies de Agave presentes en Oaxaca?

En el libro se plantean cuatro objetivos principales como los motores para la realización de esta obra. El primero radica en hacer una síntesis de la información taxonómica recabada en los últimos 240 años en Oaxaca. El segundo propone realizar una lista florística y tener un estimado de la flora local. El tercer objetivo pretende elaborar un documento para establecer prioridades de conservación biológica en el estado, y el cuarto es proporcionar información botánica confiable para el estado. El objetivo mejor logrado es el número dos y el menos atendido es el número tres. El resultado de esta primera lista florística del estado de Oaxaca es un total de especies, pero además se pudieron detectar algunos registros nuevos para el estado, y seguramente los especialistas ya detectaron numerosas especies no descritas. Estoy seguro de que no pasará mucho tiempo para que la lista de especies de este estado tenga un incremento como resultado de esta primera revisión. Aun así, quizá ya estemos bastantes seguros del número mínimo de especies que viven y crecen en este hermoso estado.

El cuarto objetivo del libro tiene una vertiente interesante, ya que a partir de su consecución se logró una presentación de las principales colecciones de plantas vivas y herborizadas ubicadas en el estado de Oaxaca, así como la inclusión de información proveniente de la principal colección de ejemplares de herbario del estado (el herbario MEXU ubicado en el Instituto de Biología de la Universidad Nacional Autónoma de México). Estos apartados serán muy útiles para quienes busquen información, pero también para quien intente obtener muestras de las plantas o de sus partes (hojas, frutos, semillas, $\mathrm{ADN}$, etc.).
Además de estos objetivos planteados, creo que los editores y todos los participantes atendieron otros objetivos que no fueron planteados de manera explícita en el libro, o que creo que se podrían alcanzar utilizando a esta obra como base. Estos objetivos son: (a) establecer un estándar de clasificación taxonómica para uniformizar la nomenclatura de diversas categorías taxonómicas. Este estándar permitirá, entre otras cosas, hacer comparables los futuros trabajos de prospección florística. Este objetivo se logró gracias a la actualización taxonómica a la que se llegó, ya que se incorporaron los tratamientos florísticos más recientes y actualizados, incluyendo los avances surgidos de la sistemática molecular. Aun así, vale la pena aclarar que el orden en el que se presentan las angiospermas no corresponde estrictamente con las clasificaciones actuales, en las que ya no se suele diferenciar las monocotiledóneas de las dicotiledóneas.

(b) Elaborar una base de datos con los principales taxa incluidos en el libro y ponerla a disposición del público en general. A mi parecer, este objetivo es uno de los principales logros del trabajo, pues la lista puede ser consultada y descargada al disco duro de una computadora de manera muy fácil. Esto permite hacer consultas rápidas, ahorrar muchas horas de captura de información, evitar errores tipográficos en la elaboración de reportes o inventarios, u ordenar a los grupos taxonómicos como a uno más le guste, entre otras funciones.

(c) Ligar la información recopilada en este libro con una base de datos disponible en internet. Este objetivo está relacionado con el gran esfuerzo realizado por la UNIBIO del propio Instituto de Biología de la UNAM. Se han capturado en formato digital imágenes de gran resolución de numerosos ejemplares del Herbario Nacional (MEXU). Además, la información de más de 38,000 ejemplares del estado de Oaxaca ya está disponible en lí- nea a través del portal de la UNIBIO (http://unibio.unam.mx).

(d) Elaborar un catálogo fotográfico de la flora de Oaxaca. Evidentemente, en este primer esfuerzo de síntesis de información botánica para la entidad no iba a ser posible lograrlo. Además, la magnitud de la flora hace difícil la posibilidad de financiar un libro con un número tan enorme de fotografías a color. De esta manera, a pesar de que el libro incluye hermosas e ilustrativas láminas de las plantas de Oaxaca, no se muestran todas las plantas del estado. Sin embargo, el gran número de especies ilustradas forman ya una base invaluable. Quizá se podría ligar el catálogo fotográfico actual del libro con la base digital en línea previamente mencionada (de la UNIBIO) y allí mismo se pueda ir enriqueciendo con más fotografías de las diversas especies.

(e) Destacar en la lista a aquellas especies que sean endémicas, exóticas, o que estén cultivadas. Los símbolos ubicados antes de cada especie indican apropiadamente en que categoría se coloca cada una de las especies; particularmente está muy claro que especie es endémica de México y cuáles lo son además del estado de Oaxaca. Sin embargo, considero que la decisión de si una especie es cultivada o no amerita examinarse con un mayor detalle y uniformidad de criterios entre los diversos tratamientos. Este rubro se torna muy importante en uno de los estados que son cuna de la agricultura en el continente americano y en donde aún continúan procesos activos de domesticación de plantas. Algunas plantas ampliamente consumidas, como el aguacate, el nanche, el chicozapote, el mamey, la ciruela criolla y el jinicuil, que seguramente tienen tanto individuos silvestres como cultivados en el estado, no están señaladas. De igual manera, se puede cuestionar porqué no se indicaron las numerosas especies que se cultivan de manera tradicional con fines de ornato, como es el caso de algunas cactáceas, crasuláceas 
y orquídeas, entre otras. Esta categorización tendrá que ser mejor trabajada, considerando todos los posibles fines de cultivo, como el alimenticio, los medicinales e industriales, los de ornato, la generación de sombra, la obtención de fibras y textiles, el control de la erosión, la construcción de cercas vivas, etc. Sin duda, la flora de Oaxaca tiene un gran potencial en todos estos ámbitos.

(f) Establecer un vínculo de reunión de los principales taxónomos interesados en el estudio de la flora de Oaxaca. Este objetivo no quedó plasmado de forma explícita en el libro, pero es uno de los más relevantes. En la obra se conjunta el esfuerzo de 127 botánicos, tanto nacionales como extranjeros. Es para mí muy emotivo ver que en la elaboración de esta gran tarea han trabajado, codo con codo, mis maestros, sus maestros y algunos de mis alumnos. No exagero al afirmar que aquí converge la participación de cuatro generaciones de botánicos, desde los más renombrados hasta los que están en plena formación. Este logro es una verdadera escuela de pensamiento centrada en la máxima casa de estudios de nuestro país. Sin embargo, también es muy relevante la participación de muchas otras instituciones, tanto nacionales como foráneas. No podría ser de otra manera; la flora de Oaxaca es un tesoro nacional que sin duda es un patrimonio de la humanidad, y que mejor manera de estudiarlo que con la participación de los más entusiastas especialistas a nivel mundial.
Podría seguir enumerando algunos otros posibles objetivos del libro, sobre todo del potencial que tiene éste más que de su contenido en sí. Pero sólo me centraré en uno más, quizá el que los botánicos más esperan: (g) establecer las bases para la elaboración de la Flora de Oaxaca. Si bien este libro es un gran cimiento para este propósito, es claro que una obra de esta magnitud sobrepasa los alcances de esta magna meta. La reflexión que tendremos que hacer en este sentido es si de verdad ya está listo el escenario para emprender tal obra. Sé que no es función de una reseña hacer este tipo de cuestionamiento, pero en este caso me parece pertinente hacerlo. Con la emoción de tener un ejemplar de esta obra en las manos, es fácil caer en la tentación de hacer castillos en el aire y pensar que la preparación de la flora de Oaxaca es factible. La verdad es que no lo es tanto si no se mejoran las condiciones para ello. Volviendo al punto inicial de esta reseña, debemos reconocer que las circunstancias de nuestro país no la hacen muy factible. No sólo me refiero a los problemas de inseguridad, que entre otras cosas están dificultando enormemente el trabajo de campo. También hay cuestiones más básicas que pueden entorpecer este fin. Las políticas de evaluación de la productividad no valoran adecuadamente a los tratamientos florísticos. En concreto, si el Sistema Nacional de Investigadores (SNI) o si las comisiones dictaminadoras de la Universidad Nacional Autóno- ma de México y de otras instituciones de investigación no toman en cuenta de manera seria a estos productos, el compromiso de los investigadores se verá gravemente menguado. De igual forma, no tengo duda de que la personalidad idónea para enfrentar este reto se concreta en el editor y compilador principal de este libro. La flora de Oaxaca representa un tercio de la flora nacional de México, cuyo tratamiento formal será sin duda uno de los sucesos científicos más importantes de nuestro país. Esta enorme responsabilidad debe ser también adecuadamente reconocida para todos los participantes, pero particularmente para su editor o su cuerpo de editores. Es mi deseo que quienes se encarguen de la conducción de esta misión se encuentren en la mejor posición y cuenten con todo el apoyo institucional posible. Tengo fe en que la flora de Oaxaca será una realidad en un futuro próximo.

Biá'si caya'ba, biaani' stilu nabé ziunenáa

(Todo va bien, tu luz siempre estará conmigo).

Eduardo A. Pérez-García

Departamento de Ecología y Recursos Naturales

Facultad de Ciencias, Universidad

Nacional Autónoma de México

México 04510, D.F., México

eduardo.perez-garcia@ciencias.unam.mx 